\title{
USO ABUSIVO DE MEDICAMENTOS
}

\author{
Dr.Paulo César Trevisol Bittencourt \\ Professor de Neurologia da UFSC \\ www.neurologia.ufsc.br \\ pcb@neurologia.ufsc.br \\ pauloctbittencourt@yahoo.com.br
}

\section{INTRODUÇÃO}

Jamais médicos dispuseram de tantas opções farmacológicas no tratamento de seus pacientes; todavia, vivemos em uma perigosa encruzilhada. Diuturnamente as indústrias lançam novas e miraculosas "hóstias farmacêuticas", a imensa maioria das quais acompanhada de ardilosa propaganda que lhes atribui um potencial fantástico e omite seus efeitos colaterais. Poucos destes novos medicamentos resistem a uma década de uso; na verdade, a maioria é abandonada após alguns anos de utilização, tempo suficiente para nos darmos conta da sua falta de eficácia ou da sua toxicidade generosa, criminosamente omitida nas suas burlas. Tragicomicamente, algumas destas drogas, mudam radicalmente de indicação com o passar dos anos, denunciando uma torpe fraude mercantilista que tem no lucro a qualquer custo sua única meta.

A Organização Mundial de Saúde nos oferece para reflexão a seguinte informação: 10 até $40 \%$ por cento das pessoas internadas em um hospital qualquer deste Mundo, têm na iatrogenia medicamentosa a sua justificativa. Note, por favor, na aritmética acima estão excluídas as cirurgias desnecessárias; com certeza, responsáveis por um número ainda mais expressivo de internações hospitalares. Por outro lado é banal ver pacientes tomando cinco, seis, sete...dez ou mais (meu record pessoal é quinze) diferentes drogas legais e obviamente intoxicados. Porém, sintomas secundários a over dosis medicamentosa são atribuídos à idade ou severidade

da sua doença (ou a ambos) e nunca identificados apropriadamente. É trágico notar como uma nova medicação é introduzida na expectativa de combater efeitos colaterais do coquetel medicamentoso prescrito. Em razão disso, muitas vezes, os efeitos tóxicos dos remédios empregados superam, e muito, as dificuldades provocadas pela doença original responsável pela sua prescrição. Notável perceber, nauseado é bem verdade, que exames complementares supostamente anormais são a pseudo-doença e a razão para prescrições estapafúrdias.

Porque prescrevemos abusivamente é uma questão intrigante e de difícil resposta. Apesar de ter consciência da sua multifatoriedade, irei tentar descrever seus principais motivadores. Infelizmente, nós médicos não somos imunes à propaganda enganosa que grassa igualmente em todas as outras áreas da sociedade. Aliás, é freqüente sermos pressionados pelos próprios pacientes e familiares, para receitarmos medicamentos com supostos efeitos fantásticos, vistos pelos mesmos, nas mais diversas formas de maquiavélico marketing comercial, muitas vezes subliminar.

Por outro lado, a competição entre nós, cada vez mais despida de qualquer vestígio ético, nos torna ainda mais vulneráveis aos apelos de natureza econômica. Assim, comportamentos francamente bizarros, outrora passíveis de punição, foram incorporados a nossa rotina como normais. Exemplificando, pesquisadores e professores de escolas médicas, em troca de algum tipo de recompensa informal, monetária em espécie ou espelhinhos à portuguesa - como nos tempos do Brasil colônia - não raro são aliciados para fazerem à apologia das novas e revolucionárias panacéias. Estudantes, ludibriados na sua boa fé, já 
médicos, tendem a seguirem de maneira acrítica os ensinamentos do falso mestre. Além disso, é notável perceber a contribuição emprestada por um ensino médico equivocado e desgraçadamente dogmático, no qual os aprendizes da arte de curar são treinados para focarem sua atenção na doença e desprezarem o doente. Assim, além de exagerarem na solicitação de exames complementares desnecessários, deixam de perceber que em inúmeras situações cotidianas, carinho e atenção, medicamentos que não possuem efeitos colaterais, são muito mais eficazes que pílulas. Mais ainda, ignoram que ao não identificarem a pessoa, através de uma judiciosa história e exame clínico, também não serão capazes de identificar a razão do seu sofrimento.

Já no século XVI dizia o suiço Philippus Aureolus Theophrastus Bombastus von Hohenheim, mais conhecido pela alcunha paterna de Paracelsus..." Todas as substâncias são venenosas; não há nenhuma que não o seja. É a dosagem certa que distingue entre o veneno e o remédio". Assim, para que não paire nenhuma dúvida, remédios são venenos que exigem sabedoria para deles se tirar algum proveito. Embora pareça anacrônico, urge o resgate deste conceito medieval para minimizarmos o sofrimento causado pelas distorções da prática médica contemporânea.

Finalmente, gostaria de lhes enfatizar um fato, são a empatia, o bom humor e o entusiasmo do curandeiro, independentemente da sua qualificação técnica, as "drogas" mais poderosas que existem. O efeito terapêutico de um determinado medicamento é diretamente proporcional à fé depositada no profissional que o prescreve. Desta maneira, demonstrar real interesse, atenção e simpatia para com as pessoas em sofrimento, constituem pré-requisito para o sucesso de qualquer tipo de terapia. Este ritual, sempre deverá ser envolvido por uma atmosfera de sincera honestidade de propósitos e de otimismo. Quando tais ferramentas são empregadas, surgem imediatamente sentimentos de confiança e fé, e aí então o que menos importa é o tipo de médico, se alopata ou homeopata. A única coisa que ele não poderá ser é burropata e ignorar preceitos básicos de fisio-farmacologia.

A medicalização excessiva é um dos grandes males da saúde atual, responsável por um número fantástico de vítimas nas mais diversas especialidades médicas. E é surreal observar que estas pessoas ignoram estarem reféns do seu próprio tratamento.

A despeito de estar ciente de que este é um tema inesgotável, comento abaixo alguns exemplos de iatrogenia cometidos pela Medicina convencional, na expectativa de que os mesmos contribuam para melhorar a vida das pessoas que buscam nossa ajuda. Muito me gratificaria que este texto encorajasse colegas de outras especialidades e igualmente pessoas leigas a exporem seus pontos de vista.

\section{ANOREXÍGENOS}

Anorexígenos são substâncias usadas com o intuito de promover aversão a alimentos e assim se obter perda de peso no usuário. Maioria delas contém anfetamina ou derivados. É verdade inquestionável que realmente promovem emagrecimento; porém, é igualmente verdadeiro que são responsáveis por inúmeros e graves efeitos colaterais. Sintomas de natureza psíquica são inúmeros. Estes incluem ansiedade, irritabilidade, euforia, melancolia reacional, surtos psicóticos, idéias suicidas, etc.

Com exagerada freqüência, pessoas usuárias destas drogas ficam prisioneiras do próprio tratamento e transformadas em pacientes psiquiátricos. Desta maneira, o benefício da redução de peso é apenado com um tributo pesado - a perda da sanidade mental. Logo, a espelhada e agradável auto-imagem emagrecida, em pouco tempo, será substituída por um perigoso sentimento de frustração. Assim, indivíduos deteriorados psiquicamente não irão tirar nenhum proveito de uma estética supostamente melhorada. Pior ainda, costuma ter um 
efeito rebote, o ganho de peso após sua supressão, costuma ser ainda maior que a perda obtida durante o período de uso.

Obesidade é uma condição complexa e, aliás, reverenciada como normal em muitas sociedades; assim, para uma melhor compreensão da mesma, seus acometidos deveriam ser objetos de judiciosa avaliação médica e psicosocial. Por isso mesmo, abordagens apropriadas deveriam levar em conta aspectos da personalidade e a maneira de viver do indivíduo. Por outro lado, é comum ver formulações mágicas, desenvolvidas por mercadores inconseqüentes e para uso coletivo. Ora, ao não considerar a pessoa, com certeza, todas serão fraudulentas e somente por mero acaso irão atingir seu alvo. Algumas delas, de tão bizarras, promovem uma rápida ruína psíquica; não constituindo raridade ver suas vítimas cometendo suicídio, devido à ação depressiva de alguns componentes da fórmula.

É triste observar que o diagnóstico ou sentimento de obesidade, muitas vezes, é de natureza psicogênica; isto é, ela não existe de fato, sendo induzido artificialmente por modismos de beleza extravagantes. Fora desta discussão estão aquelas pessoas vitimadas por obesidade mórbida. Estas deveriam ser consideradas para um tratamento adequado e dispensadas do uso nefasto de anfetaminas.

\section{A TRAGÉDIA BARBITÚRICA}

Fenobarbital (PB) foi descoberto na Alemanha em 1912, precisamente no dia de Santa Bárbara, inspiradora do seu nome. É a droga barbitúrica mais usada no mundo. No Brasil é comercializada com os nomes de "gardenal" e "edhanol".

Em primeiro lugar, gostaria de lhes reafirmar uma convicção: barbitúricos são altamente eficientes para impedir a recorrência de ataques epiléticos diversos. Sinceramente, não vislumbro dentre as atuais drogas antiepiléticas (DAE), alguma com eficácia superior. Contudo, a performance de uma DAE não pode ser medida exclusivamente pela sua habilidade em anular epilepsia; assim, seus potenciais efeitos negativos nunca deveriam ser perdidos de vista pelo terapêuta responsável. Com relação a PB, demoramos excessivamente para reconhecer seu mais grave problema: é extremamente difícil encontrar um usuário crônico que não desenvolva barbiturismo, isto é, a combinação de sonolência (ou paradoxal hipercinesia) com transtornos cognitivo-comportamentais em grau variado. Como crianças e adolescentes são particularmente vulneráveis, é possível inferir o fantástico número delas que foram desgraçadas pelo uso abusivo de PB até recentemente entre nós. Muitos dos seus usuários, prisioneiros do próprio tratamento, foram transformados em pacientes psiquiátricos e encaminhados para "tratamento especializado" em deprimentes masmorras psiquiátricas espalhadas pelo país, onde profissionais incapazes de identificar a óbvia origem das suas dificuldades, não somente aumentavam a dose do "medicamento", bem como prescreviam outras drogas, igualmente não inocentes, para o "tratamento" dos típicos efeitos barbitúricos, consagrando uma brutal iatrogenia. Além disso, depressão grave induzida pelo seu uso prolongado, é demasiado freqüente para ser ignorada, e, com toda certeza, foi responsável por muitos dos suicídios vistos na população sofredora de epilepsia. Por isso, deveríamos dar um basta definitivo na tragicomédia representada pela prescrição de medicação antidepressiva para o tratamento deste comum efeito colateral.

Para aqueles que tão obstinadamente defendem seu emprego indiscriminado, sugiro uma pausa para reflexão: será que os fabulosos escritores Dostoiévski e Machado de Assis teriam a mesma produção literária tomando PB diariamente? Imaginem o desastre que seria Júlio César ou Alexandre da Macedônia liderando campanhas militares, ingerindo PB todas as noites. O imperador romano então, caso conseguisse atingir Cairo, certamente desapontaria 
sua amada devido a impotência barbitúrica e muito provavelmente iria usar uma saída britânica...Cleo: I am british, no sex please! Ou, formulando a mesma questão de uma forma mais abrangente: cite algum grande personagem, de qualquer área do saber, sofredor de epilepsia como os quatro indivíduos mencionados e medicados por tempo prolongado com PB. Qual?

Muito provavelmente, a crença na eficácia monstruosa desta droga entre médicos, deve-se a sua ignorância da evolução natural da maioria das epilepsias: cura espontânea com o tempo. Assim, é melancólico atribuir a PB, ou aos seus próprios poderes, algo que aconteceria naturalmente.

Realço; neste princípio de século presenciamos PB sair de panacéia antiepilética para a de vilão; sobrando, todavia, indicações para sua utilização. Aliás, há urgente necessidade de um consenso para a definição de quando e como usá-lo; pois, em casos especiais, PB persiste sendo a única opção medicamentosa eficaz. Apesar disso, gostaria de lhes enfatizar mais uma vez... todos os indivíduos sofredores de epilepsia deveriam ter uma oportunidade de viverem sem os inconvenientes das drogas barbitúricas.

Atenção: como PB continua sendo exageradamente prescrito entre nós, é comum encontrarmos pessoas com transtornos cognitivo-comportamentais secundários ao seu emprego. Aliás, em nossa sociedade é lamentavelmente freqüente vermos crianças e adolescentes vítimas deste abuso terapêutico, tendo péssimo rendimento escolar e comportamental; muitas delas estarão exibindo o rótulo de deficiente mental, sem na verdade o serem; e, pior ainda, induzidos a delinqüência.

\section{FENITOÍNA OU FEIOTOIINA}

Pesquisadores norte-americanos, prováveis misóginos radicais, descobriram fenitoína (PHT) ao final dos anos trinta do século passado e a apresentaram ao mundo como "grande droga antiepiléptica, indispensável no tratamento de pessoas com epilepsia". Enfim, tínhamos uma droga mágica, aparentemente com "eficácia superior ao fenobarbital e menor toxicidade". E quando se ganha uma guerra, a versão do vencedor passa a ser verdade inquestionável, geralmente assumindo caráter de dogma religioso. Apesar do estardalhaço inicial, PHT revelou ser uma droga com espectro de ação semelhante ao PB alemão e com efeitos negativos também. Alguém então sugeriu, hipoteticamente, que a combinação de PB com PHT teria efeito sinérgico e assim finalmente surgiu a "medicação ideal", alcunhada de "comital" e difundida amplamente pelo universo.

Durante décadas, PHT (associado ou não a fenobarbital) foi usada massivamente no tratamento de pessoas com epilepsia, sem que ninguém ousasse comentar seus inúmeros e freqüentes efeitos colaterais desagradáveis. PHT é considerada uma droga antiepilética MAIOR e não discordamos disso; porém, todos que a prescrevem generosamente, deveriam igualmente ter em conta que ela é também a MAIOR causa de feiúra medicamentosa da atualidade. Aliás, neste aspecto, seu potencial é tão dramático que melhor seria chamá-la de "feiotoína", tal a desgraceira estética que geralmente provoca nos seus usuários. Particularmente as mulheres pagaram um pesado tributo no passado (e muitas seguem sendo desfiguradas no presente), sendo alijadas do convívio social por apresentarem a síndrome feiotoínica clássica: brutal halitose, consequência de sangramentos provocados por gengivite hiperplásica; hirsutismo sutil ou generalizado e acne difusa.

Contudo, muitos colegas ainda têm a percepção dos seus defeitos ofuscados por uma crença fundamentalista em sua eficácia antiepilética; provável subproduto da colonização 
norte-americana. Desta maneira, sofismam sistematicamente na ânsia de enfatizarem suas virtudes e omitirem seus graves defeitos. É possível que feiúra confira status social em algumas sociedades desenvolvidas; mas, entre nós latinos, seguramente não. Num país ainda dominado pela ideologia machista, mulheres sofredoras de epilepsia já serão naturalmente discriminadas; dispensável agregar-lhes defeitos artificialmente criados. Por isso, preservar os indivíduos sofredores de epilepsia, em especial mulheres, dos inconvenientes comuns desta droga, deveria ser uma meta a ser perseguida por todo médico crédulo no sábio dito popular: prevenir é sempre melhor que remediar. Mais ainda, se levarmos em conta os honorários cobrados por dentistas, esteticistas, psicólogos e cirurgiões plásticos; profissionais geralmente envolvidos na tentativa de reparação.

Assim, mulheres, não importando qual faixa etária, deveriam ser poupadas da brutalização estética provocada por esta droga, que excetuando situações emergenciais, jamais deveria ser empregada como primeira opção no tratamento das suas epilepsias.

Infelizmente, misóginos existem, e em qualquer profissão. Porém, para aqueles que inocentemente patrocinam tal sorte de desatino, por uma fé messiânica na eficácia desta droga, urge um comentário adicional...doutor, o senhor com certeza prescreveria PHT para sua ex-mulher, mas recomendaria seu uso para sua filha ou para sua amante?

Atenção: Fenitoína é vendida no Brasil com os nomes fantasias de "hidantal" e "epelin".

\section{TOPIRAMATO}

Esta é a droga da onda. Foi desenvolvida como droga anti-epilética nos anos oitenta do século passado. E recebeu um alto investimento marqueteiro para se viabilizar como tal. Inúmeros relatos científicos, imensa maioria feitos sob encomenda e publicados nas revistas médicas mais confiáveis (sic), davam conta da sua eficácia em pessoas sofredoras de epilepsias parciais. Como droga anti-epilética revelou-se um fiasco; todavia, por casualidade, foi reconhecida como medicação eficaz na prevenção de ataques de enxaqueca - a prima irmã da epilepsia. Além disso, descobriu-se um efeito colateral, notável nos dias atuais - era emagrecedora. Pronto, eis aqui a medicação ideal para o tratamento das mulheres gordinhas sofredoras de enxaqueca.

Atualmente, é uma das drogas mais prescritas neste Brasil varonil. Impossível negar sua eficácia anti-enxaquecosa e de inibidora do apetite. Impossível negar também ser medicação de primeira escolha naquelas pessoas vitimadas pelo binômio epilepsia/enxaqueca; uma combinação mórbida freqüente, e, em qualquer sociedade. Porém, deveria ser igualmente impossível ignorar seus efeitos negativos. Não raro, apesar da sua eficácia na prevenção de ataques enxaquecosos ou epiléticos, ela deve ser suprimida pelo tormento que provoca na memória da usuária. Várias vezes escutei a mesma queixa e por isso mesmo faço questão de reproduzi-la ...doutor, estou bem em relação aos meus ataques; mas eu não consigo lembrar de nada.Em alguns momentos sinto-me perdida; não sei quem sou eu, o que faço, aonde moro e... etc.

Por isso, médicos atentos não deveriam perder de vista este trivial efeito colateral. Bem claro para mim que qualquer tratamento irá cobrar um tributo; mas convenhamos, a aniquilação da memória é demasiado exagerada para ser tolerada como tal. Observo que nenhum tratamento, seja ele qual for e por mais benéfico que seja, justificaria a perda da capacidade mental original. Afinal, se este for o preço cobrado para não ter crises, qual o ser racional que aceitaria pagá-lo? Mil vezes melhor seria seguir o calvário provocado por crises do que ficar livre das mesmas, mas com o cérebro mutilado e desprovido das suas virtudes de fábrica. 


\section{INAS, UM MODISMO PERVERSO}

Fluoxetina, paroxetina, sertralina, etc; são consideradas as modernas panacéias contra a síndrome que grassa atualmente no mundo: tédio e melancolia mesclados com ansiedade recorrente. Tais sintomas costumam ser equivocadamente interpretados como sintomas de genuína depressão. A vida moderna é pródiga em fatores desencadeantes de transtornos emocionais. Na verdade está cada vez mais difícil encontrarmos o parceiro ideal e, mais ainda, um trabalho que seja gratificante e prazeroso. Algumas vezes se acha, mas o ambiente é demasiado insalubre e o assédio moral é uma aberração freqüente. Por outro lado, os meios de comunicação também não nos oferecem trégua. Por TV, rádio, jornal e internet, nossos cérebros são atormentados diuturnamente com insultos e propostas de qualquer natureza. Outrora se limitavam a estímulo consumista; porém, a modernidade agregou diversas alternativas e hedonismo a qualquer custo, talvez seja o principal. Como a Internet não dorme, não há mais insônia e solitário passou a ser palavra para definir o indivíduo que consegue dormir. Diante desta atmosfera moderna insana, com violência super banalizada, é absolutamente normal sobrevirem sintomas tais como tédio, frustração, raiva, desespero, idéias suicidas/homicidas, sexualidade aberrante e assim por diante.

Tais sintomas são agravados quando o Estado abdica de ser um agente educador e norteador da ética. Mas se levássemos em conta o exemplo da Itália nos anos setenta do século passado, chegaríamos à certeza de que qualquer sociedade pode se organizar e progredir apesar da atuação desastrada do poder estatal.

Por outro lado, Depressão é uma condição grave e que certamente existe. Quando identificada deveria ser tratada seriamente; entretanto, seu diagnóstico foi extremamente inflacionado entre nós. A maioria das pessoas que dizem sofrer de DEPRESSÃO, e tratadas farmacologicamente como tal, não são originalmente depressivas. São indivíduos expressando a sua maneira as vicissitudes da vida contemporânea, socialmente medíocre, onde Ansiedade com pitadas de Melancolia reacional são a regra geral. Todavia, há um grande e indisfarçável interesse econômico por traz desta prática censurável. Introduzida pioneiramente por uma multinacional norte-americana em 1987 com o prosaico nome de "prozac", fluoxetina ganhou o mundo como a droga da felicidade. Sem qualquer escrúpulo, a droga revolucionária ganhou ares de solução para todos os "póbremas", independente de como eles fossem qualificados; não importando se eles fossem de natureza conjugal, social, econômico ou enigmaticamente rotulado como psicológico. Enfim tínhamos uma droga mágica. E os filmes de Hollywood foram exemplares na sua propaganda. Recordo-lhes de uma cena exibida em um filme de Woody Allen, excelente comediante, mas desonesto mercador, onde no bidê do bom personagem havia uma caixa de prozac, configurando a mais asquerosa e detestável propaganda; pois, subliminar, registra no cérebro do espectador aquilo que seus olhos mal percebem. Desprezouse por anos, a observação crescente entre médicos e pacientes de que os usuários estavam expostos a inúmeros efeitos negativos, entre os quais a abolição da sexualidade é quase uma constante e ideação suicida freqüente. Alguns profissionais, cooptados pela indústria ou simplesmente néscios na arte, chegaram ao cúmulo de afirmar que... as pessoas agora cometem suicídio graças ao prozac que Ihes deu coragem para fazê-lo.

Com seu estrondoso sucesso mercadológico, outras "inas" de multinacionais concorrentes, seguem brotando ao natural. No momento, já temos dezenas delas disputando este generoso "mercado da insanidade coletiva"; contudo, é dispensável qualquer bola de cristal para antever que "inas" ainda mais modernas que estas surgirão nos próximos anos. Seus arautos, bem pagos, continuarão enfatizando a velha lenga-lenga - doutor, esta é a droga que solucionará os problemas existenciais dos seus pacientes. Grotescamente se finge ignorar que não existem medicamentos capazes de solucionar diferenças conjugais crônicas 
ou deterioração psíquica induzida por um trabalho desagradável. Pior ainda quando não levam na devida conta que a abolição da sexualidade no usuário é um trivial efeito colateral que liquidará qualquer relacionamento. Além disso, não existem medicamentos para tratar assédio moral ou social, cada dia mais freqüente entre nós; enfim, que não existem formulações mágicas para tratar um indivíduo vivendo em desacordo com sua proposta existencial, seja ela qual for.

Finalmente neste tópico, gostaria de Ihes recordar um acontecimento. Há cerca de quatro anos, matando tempo, li um especial da revista VEJA, dedicado às mulheres do Brasil (sic). Intitulava-se "Mulheres de A-Z". Lia com toda atenção e lhes confesso que buscava no texto alguma novidade capaz de me ajudar a compreender o comportamento único das mulheres; porém, quando cheguei na letra "Z", fiquei indignojado. Z significava "zoloft" e dizia mais ou menos assim...finalmente nós mulheres agora temos um medicamento para solucionar nossos problemas afetivos/depressivos, peça ao seu médico lhe prescrever "zoloft", pois zoloft is all. Torpe propaganda; pois, este é o nome comercial pioneiro de sertralina. Escrevi, no mesmo dia, uma carta eletrônica ao editor comentando sobre os malefícios da propaganda enganosa veiculada pela revista; e, com paciência budista permaneço aguardando sua resposta. Logo, sugiro tomarem cuidado com revistas semanais deformativas, pois elas podem não ser tão éticas quanto apregoam ser.

Definitivamente, penso que a humanidade deveria dedicar mais tempo a meditação/ reflexão; e, além disso, buscar os prazeres oferecidos pelo contato com a natureza pródiga que nos rodeia. E este reencontro com a simplicidade existencial ofereceria a ela uma boa perspectiva de uma vida despilulalizada e gratificante.

\section{DIAZEPAM E DERIVADOS}

Diazepam é uma droga fabulosa para diversas situações. Por exemplo, não há medicamento igual para combater ansiedade, uma praga na sociedade moderna e também para interromper rapidamente ataques de epilepsia. Ela foi descoberta no final do século XIX e somente ao fim da II Guerra Mundial começou a ser utilizada. Neuropsiquiatras poloneses, a quem cabe a primazia do seu uso pioneiro, na capital Varsóvia semi-destruída e com uma população atormentada por ansiedade, testaram e ficaram maravilhados com sua eficácia. Comercializada pela multinacional Roche, ganhou o mundo com o nome fantasia de "valium". Nas últimas cinco décadas desenvolveram-se cerca de 15-20 derivados desta droga, maioria delas tem em comum o sufixo "am"; assim surgiram: bromazepam, clonazepam, lorazepam, alprazolam, clobazam, midazolam, etc.

Qual o problema com droga tão boa? Não levamos em consideração que seu uso deveria ser circunstancial; isto é, deveria ser restrito àquelas situações de extrema ansiedade (ou para abortar crises de epilepsia prolongadas), incontroláveis por qualquer outro método não medicamentoso. Dependência, similar àquela provocada por álcool, é freqüente; além do fenômeno da tolerância... doses crescentes para se obter o mesmo efeito. Todavia, pior que estes defeitos, foram a constatação de que seu uso exagerado e por tempo excessivo, estava associado com prejuízo da memória recente e sintomas depressivos. Muito provavelmente, um contingente enorme de pessoas sofredoras de "depressão" da atualidade, tem no uso crônico de diazepam - ou derivados - a sua causa. Mais ainda se levarmos em conta, que muitos destes indivíduos também são consumidores de álcool, duas drogas que por atuarem em sítios semelhantes do sistema nervoso, tem seus efeitos potencializados.

Impossível deixar de ignorar o risco que benzodiazepínicos trazem para sofredores de transtornos do sono; em particular àqueles que roncam; estes passam a ter o risco de apnéia durante o sono aumentado sensivelmente e assim ficam expostos a doença vascular obstrutiva, 
em quaisquer órgãos.

Apesar de tudo, é previsível que drogas benzodiazepínicas, devido sua alta eficácia no combate a ANSIEDADE, um tormento na sociedade moderna, serão parte do nosso arsenal terapêutico por incontáveis séculos adiante. Porém, um emprego sábio das mesmas é requerido. E minha "bola de cristal" sugere que elas deveriam ser SEMPRE privilegiadas no tratamento daquelas pessoas sofredoras de ataques recorrentes de ansiedade, mas por um tempo limitado, discutido entre todos os envolvidos na sua assistência.

\section{ASPIRINA E HEMORRAGIA DIGESTIVA}

Se é Bayer é bom? Nem sempre! Aspirina, também conhecida por AAS (ácido acetil salicílico), foi usada pioneiramente pelos chineses há milhares de anos. Eles a obtinham intuitivamente através de um chá com a casca do "chorão"; um preparado hábil para combater dor e febre. Ao final do século XIX, pesquisadores alemães a sintetizaram em laboratório e esta descoberta enriqueceu a multinacional alemã, sendo seu "carro chefe" por muitas décadas. Claro que a milenar aspirina é uma boa alternativa em diversas situações, particularmente como antiagregante plaquetário (= afinador do sangue) na atualidade; porém, é obrigação reconhecer que esta droga aparentemente inocente é responsável por diversas internações emergenciais. É, muito provavelmente, a causa mais banal de sangramentos digestivos de intensidade variável. Por outro lado, é bem sabido que álcool potencializa sua natural agressão à mucosa gástrica; aliás, esta é uma combinação infeliz, freqüentemente associada com episódios de hemorragia digestiva. Assim, transmita aos seus que medicamentos contendo aspirina nunca deveriam ser usados na prevenção ou tratamento da vulgar ressaca. Além disso, mantenha sob vigilância todo o usuário prolongado desta substância, mesmo que em doses diárias mínimas. Caso estes desenvolvam anemia, hemorragia digestiva crônica é o diagnóstico primeiro e seu emprego deveria ser imediatamente suspenso. E jamais cometam a insensatez de usá-la em uma pessoa sob suspeição de dengue; uma condição ainda epidêmica em vários locais do mundo, cuja variante hemorrágica será piorada por esta substância.

Ironicamente, há anos é veiculado na mídia o nome de um produto espetacular para prevenir ressaca. Chama-se "engov" e um dos constituintes da sua fórmula é ASPIRINA. É possível inferir o número exagerado de usuários que desenvolvem hemorragia digestiva no dia seguinte a noites generosas. E é de se lastimar o silêncio cúmplice das autoridades sanitárias.

\section{CINARIZINA E FLUNARIZINA - DROGAS LEGAIS?}

Desde há cerca de 30 anos estas drogas são bizonhas panacéias antilabirinto. $\mathrm{Na}$ verdade são prescritas para todo infeliz em nossa sociedade que ouse se queixar de "tontura". Elas são oferecidas nas farmácias nacionais com 10-20 nomes comerciais diferentes, sendo "stugeron" (cinarizina) e "vertix" (flunarizina) os mais conhecidos. Ambas possuem habilidade ímpar para bloquear um neuro-transmissor muito importante chamado dopamina, essencial na modulação do humor e da motricidade também. Criminosamente suas "burlas" não dão à devida atenção; bem ao contrário, ao enfatizarem seus formidáveis efeitos cerebrais induzem a automedicação (melhor seria dizer auto-intoxicação). E colegas médicos, ludibriados na sua boa fé, seguem prescrevendo quantidades generosas destas substâncias. Em conseqüência do progressivo bloqueio dopaminérgico, dois sintomas graves se manifestam: melancolia e/ 
ou parkinsonismo. Assim, é uma desagradável rotina encontrarmos vítimas de intoxicação crônica por estas drogas, ostentando os diagnósticos de Depressão ou de doença de Parkinson, não raro coexistindo na mesma pessoa. A tragicomédia é incrementada de modo dantesco quando médicos especialistas, ao invés de identificá-las como etiologia e suprimi-las, recomendam medicamentos antidepressivos e antiparkinsonianos para o tratamento de seus vulgares efeitos colaterais.

Por favor, tenha em conta que tontura é um dos sintomas mais comuns em qualquer consultório médico (e igualmente em salão de cabeleireiros) e como pode expressar distintos problemas de saúde, sua causa deveria ser objeto da mais judiciosa avaliação clínica em todos os seus sofredores. Entretanto, como cinarizina/flunarizina foram guindadas a posição de panacéia para o seu tratamento, é possível imaginar a quantidade enorme de pessoas iatrogenizadas pelo uso destas substâncias entre nós. Como indivíduos idosos são os mais vulneráveis aos seus efeitos tóxicos, recomendo-lhes fortemente investigar o uso destes medicamentos em todos seus conhecidos, amigos ou familiares que estão em tratamento por suposta doença de Parkinson ou Depressão. Tenho firme convicção que irão encontrar um fantástico número de flagelados pelo uso delas. Por esta razão, embora legais, urge um controle das mesmas, restringindo sua compra e inibindo a auto-intoxicação. Além disso, todos os produtos comerciais contendo estas substâncias deveriam ter claramente expresso em suas bulas: ATENÇÃO, O USO DESTA SUBSTÂNCIA PODE CAUSAR SINTOMAS DE DEPRESSÃO E DE PARKINSONISMO.

\section{NEUROLÉPTICOS}

Drogas neurolépticas são utilizadas fundamentalmente no tratamento de desordens neuropsiquiátricas; em especial nos vitimados pela síndrome esquizofrênica. Clorpromazina, um derivado fenotiazínico, foi a droga pioneira deste grupo. Ela foi lançada nos anos cinqüenta do século passado e os resultados iniciais foram intensamente celebrados. Os mais entusiasmados afirmavam que a síndrome esquizofrênica seria exterminada. O tempo demonstrou que quem seria exterminado eram os próprios pacientes, graças aos seus inúmeros efeitos deletérios. Grande parte da população usuária desenvolveu com o passar dos anos, terríveis transtornos motores denominados de Discinesia Tardia. E tais alterações são definitivas, inexistindo qualquer tratamento eficaz. E a paquidérmica psiquiatria ortodoxa deveria ser incriminada por mais este crime.

Recentes descobertas têm sido feitas, resultando em neurolépticos com menor toxicidade motora e que por isso mesmo, promovem um melhor convívio social. Entretanto, é necessário ainda um bom tempo de observação para que esta impressão inicial se confirme e que seus efeitos negativos, alguns ainda incógnitos, se manifestem.

Todavia, é dispensável qualquer sentimento iconoclasta para se ter à percepção de que disfunções neuropsiquiátricas exigem algo mais que medicação. Estas pessoas deveriam ter acesso a métodos que privilegiem práticas humanistas que resgatem sua convivência social. E há inúmeras opções não farmacológicas para se obter isso. Com certeza, deveríamos aprender com as sociedades rotuladas como "primitivas"; pois, embora possa parecer paradoxal, elas ainda possuem vestígios de cultura verdadeiramente humanista da qual poderíamos tirar algum ensinamento. 


\section{DIGITAL}

Digitalis purpúrea ("digoxina", "digitoxina”) tem sido usada como droga cardiotônica desde há séculos. Identificada como causa de arritmias cardíacas sérias, no momento está sendo abandonada. Deixa um rastro formidável de mortes. É muitíssimo provável que milhões pereceram graças a seus efeitos colaterais, tardiamente reconhecidos. Paracelsus foi mais uma vez ignorado... a dose apropriada era infinitamente menor daquela que se supunha como ideal.

Um efeito colateral positivo? Como curiosidade atribui-se a esta substância alguns dos maravilhosos quadros do pintor holandês van Gogh. Razão? Xantopsia (=visão amarelada) é um dos seus efeitos colaterais mais triviais e é fato bem documentado que ela foi empregada no seu tratamento; pois à época lhe eram atribuídas propriedades anti-psicóticas. Assim, a fase da sua produção amarelada deve ser creditada ao digital. Novamente mal empregado, afinal esta pessoa genial sofria de epilepsia, sobre a qual nenhum benefício é observado.

\section{ANTI-INFLAMATÓRIOS NÃO HORMONAIS}

Certamente que são capazes de aliviar dores diversas, particularmente das articulações, e poucos da nossa espécie depois dos quarenta anos estará livre deste tormento. A maioria de nós, à medida que envelhecemos irá sofrer de artrose, um tipo benigno de reumatismo. A sapiência popular refere-se a este fenômeno fisiológico com bom humor, é a idade do condor dizem. Ora com dor aqui, ora com dor acolá. Contudo, todas estas drogas possuem diversos efeitos indesejáveis. Por exemplo, nefrotoxicidade importante e, além disso, agridem a mucosa gástrica de maneira análoga à aspirina, que, aliás, está inserida neste grupo. Graças a um marketing bem sucedido são consideradas inocentes; diclofenato de sódio, a principal delas, é largamente prescrita, ensejando grotesca subestimação da sua toxicidade. Em conseqüência, casos de perfuração gástrica repetem-se nas emergências configurando uma entediante e perversa farsa. E muitos sofredores de Hipertensão Arterial Sistêmica e de Insuficiência Renal têm no seu uso crônico a mais óbvia causa.

Ainda mais recentemente, um suposto revolucionário antiinflamatório, vendido com o singular nome de "prexige", foi identificado como promotor de inúmeras mazelas físicas e por isso seu emprego tem sido questionado. Mas, outros se seguirão e com conseqüências similares; por esta razão, a sociedade deve "pré-exigir" doravante testes toxicológicos sérios para todas as novidades farmacêuticas. Além disso, esta aberração deveria nos alertar para uma busca por alternativas não medicamentosas e eficazes no tratamento de pessoas sofredoras de dor crônica.

\section{ANTI-HIPERTENSIVOS}

A pressão arterial das pessoas tende a um aumento gradual com o passar dos anos e, além disso, ela sofre oscilações ao longo do dia. Tais fatos são frequentemente ignorados. Assim, é comum encontrarmos pessoas exibindo sintomas de hipotensão arterial, tais como tontura, fraqueza, sonolência diurna, etc, em uso de medicação anti-hipertensiva; pois foram equivocadamente diagnosticados e tratados como sofredores de Hipertensão Arterial.

Recordo-lhes que até recentemente o uso abusivo de diuréticos para o seu tratamento, era a causa mais comum de câimbras (devido diminuição do nível sanguíneo de potássio) e como ainda são muito utilizados, o uso destas substâncias deveria ser checado em todo 
indivíduo que as exibe, particularmente quando associadas a fraqueza e tremor em mãos.

Drogas beta-bloqueadoras (propranolol, atenolol, metoprolol, etc) devem igualmente ser objeto de comentários. Elas constituem um grupo de substâncias empregadas em diversas situações, particularmente em sofredores de Hipertensão Arterial Sistêmica e de Insuficiência Coronariana (angina pectoris); e, na Neurologia, como profilático de ataques enxaquecosos. Todavia, também estão associados com inúmeros efeitos desagradáveis. Destacando-se fraqueza universal (síndrome miastênico); insônia/alucinações; impotência sexual, entre outros. Além disso, podem desencadear ataques de asma e dificultar o controle de diabetes mellitus. Embora constituam drogas muitas vezes indispensáveis, seus efeitos colaterais nunca deveriam ser perdidos de vista.

É importante observar que Hipotensão Arterial Sistêmica, de maneira análoga a Hipertensão Arterial Sistêmica, expõe a vítima a um risco significativo de doença vascular obstrutiva; infartos cerebrais ou cardíacos são as complicações mais graves.

\section{BотоX}

A sociedade ocidental é realmente insaciável na busca da felicidade. Desde há séculos, consome álcool em doses cavalares para acalmar seus demônios; descobriu as drogas benzodiazepínicas na década de 60 e desde então se empanturra delas; e a partir de 1987 (ano da pioneira - fluoxetina) encontrou equivocadamente nas "inas" a solução de tédio crônico mesclado com ansiedade recorrente. Difícil encontrar uma mulher atualmente que já não as tenha experimentado. Aliás, dificílimo encontrar uma de meia idade que não esteja em uso de alguma delas. A moda bizarra pegou até entre veterinários; pois cachorros e gatos urbanos, seqüestrados em apertamentos, naturalmente adoecem e surrealmente também estão sendo "tratados" com estas panacéias.

Como a existência continua sofrida... afinal sempre há algum defeito grave para ser corrigido, explodiram as clínicas de cirurgia plástica; e, a bem da verdade, um fenômeno não restrito a tropicalândia. Assim, chegamos na reparação estética como a solução ideal para uma problemática de relacionamento milenar. É cirurgia para tudo e para todos também; não havendo limites de nenhuma espécie. Na expectativa de conquistar clientes afetados por vaidade doentia, até o baixo clero tem sido contemplado com financiamento. $\mathrm{E}$ o número de vítimas incrementa na mesma proporção; ora, se procedimentos de risco são vulgarizados, tragédias acabam banalizadas no cotidiano.

Para piorar a situação eis que chega a toxina botulínica como medicamento espetacular. Botox é o nome comercial mais afamado da coisa. Para os mais novos, segue uma informação adicional. Toxina botulínica é aquela mesma velha conhecida das nossas avós; elas a temiam quando faziam suas conservas artesanais e por isso mesmo tinham cuidados especiais no seu preparo. Elas sabiam de uma doença antiguíssima e freqüentemente fatal chamada botulismo - paralisia do corpo devido intoxicação por toxina botulínica veiculada em conservas mal preparadas. Pois bem (deveria escrever pois mal), pesquisadores na década de oitenta, descobriram nela uma boa alternativa para tratamento sintomático de diversas condições neurológicas que cursam com rigidez muscular ou distonia. E realmente é mister lhes dizer que ela poderá ser de grande utilidade em algumas destas situações. Todavia, extrapolou-se abusivamente sua indicação e atualmente, pasmem, ela concorre com a cirurgia plástica no mórbido afã de perpetuar beleza estética. E definitivamente virou moda social. Assim como temos alopatas, homeopatas, agora temos também os botoxisopatas que usam "à bangu" seu poderoso "medicamento" anti-velhice.

O frenesi é tal que efeitos destes modismos são evidentes em qualquer roda social 
composta por indivíduos pertencentes às classes alta e média, e em curto tempo, serão igualmente perceptíveis entre freqüentadores de bailões da periferia. Dias atrás uma amiga espirituosa contou-me detalhes de um baile aristocrático em que participou. Tive acessos de risos com seu relato. Jamais irei declinar seu nome, tão-pouco o local onde isto aconteceu; mas é bastante provável que o mesmo possa ser visto em qualquer outra cidade brasileira. Inspirado nela segue este relato...."Paulo, o tamanho da barriga é uma das causas físicas, em todos os sentidos, de separação dos casais de meia idade; ah, e as rugas e o tamanho dos seios também. A lipoaspiração resolveu o primeiro deles; botox liquidou as rugas; e baldes de silicone fizeram as mulheres voltarem a exibir as mamas da mama. O problema é que os desencontros permanecem; se agora já é possível as partes baixas se roçarem durante uma dança, o tamanho exagerado do peitoril duro impede um contato pleno e o que é pior, como manifestar tesão por alguém incapaz de sorrir. Seria mil vezes preferível ver o rosto da amada, mesmo enrugado, demonstrar alguma emoção, do que contemplar uma face botoxicada, estilo oriental, onde além de ser impossível vislumbrar sua idade, desgraçadamente ignora-se seu sentimento. “

Como Homem, constato aborrecido ver homens aderirem à moda da vaidade mórbida; eles estão igualmente se embotoxicando, se lipoaspirando e se siliconizando também. Humanos deveriam tentar manter a serenidade, a qualquer custo; até para justificar a auto adjetivação sapiens. Talvez a meditação seja um eficaz medicamento contra este flagelo transformista que deteriora suas vidas. Talvez qualificados psicólogos possam ser úteis. Mas, um maior contato com a natureza, cujos efeitos positivos são subestimados na sociedade moderna, dispensaria qualquer comentário adicional. Porém, desconfio que egocídio seria indispensável na resistência a modismos bizarros. Liberdade, sem adjetivação, é a solução, e para todos os animais, independentemente da sua qualificação zoológica.

\section{COLESTEROL}

Um outro assunto interessante a ser comentado neste artigo é o relacionado à cultura do colesterol. Durante décadas, o aumento sérico do colesterol total foi venerado por nós, como um inimigo a ser combatido ferozmente e, aliás, muitos médicos gastaram (alguns continuam gastando) sua vida fazendo esta apologia. Atingimos o orgasmo científico quando descobrimos a dualidade do bom e do mau colesterol. Apesar disso, reconheço não haver dúvida quanto a sua contribuição na gênese da doença vascular obstrutiva, particularmente quando níveis exagerados são detectados. Todavia, considerando hipercolesterolemia como um grande fator de risco para o desenvolvimento de aterosclerose, obrigamos milhões de indivíduos mundo afora, modificarem seus hábitos alimentares tradicionais, na expectativa de protegê-los contra um dos principais males deste século. Recordo até uma cena da minha infância, com nossa mama, ludibriada na sua boa fé, ordenando a nossa secretária: Benta, banha e manteiga never more, de agora em diante faça todas as frituras com seboclim. E como nossa comida trivial; mas, excelente, se maquidonaldizou tão de repente! A resultante deste processo, em termos de colesterolemia, imagino ser zero.

Entretanto, contestando parcialmente este mito, um artigo proveniente de uma das mais tradicionais universidades holandesas e publicado recentemente, afirma textualmente em suas conclusões... em pessoas acima de 85 anos de idade, concentrações altas de colesterol total estão associadas com maior longevidade e menor mortalidade por câncer e infecções. Pensem comigo, vale a pena ser tão radical em recomendações nutricionais para pacientes idosos, sonegando-lhes o prazer de consumirem alimentos à que estão habituados há décadas?

Encerrando este tema, uma questão básica; afinal, qual seria o nível normal de 
colesterol? Ninguém sabe! Mas, o uso de sinvastatina (ou similares) na atualidade, para sua redução, é tão exagerado que torna impossível ser ignorado. Com certeza é mais um modismo ridículo. É tragicômico notar a generosidade na sua prescrição; sendo raridade na atualidade não vê-la incluída no rol de medicamentos usados por pessoas de mais de cinqüenta anos de idade. Tal qual fluoxetina, especialistas das mais diferentes áreas, convencidos da sua eficácia protetora, estão prescrevendo-a de modo indiscriminado. Infelizmente não levam em conta seus efeitos colaterais e por esta razão é fato corriqueiro ver seus usuários ostentarem o diagnóstico de fibromialgia. Ora, dores musculares são um dos efeitos mais vulgares desta droga e sua simples supressão, por si só, eliminaria mais uma doença artificialmente provocada.

\section{EXEMPLOS DE IATROGENIA NÃO MEDICAMENTOSA}

Seguem três exemplos de iatrogenias não medicamentosas. A primeira delas, praticada largamente até recentemente, foi a moda da botinha ortopédica. Esta era recomendada sistematicamente para desafortunadas crianças supostamente sofredoras da síndrome do pé chato. Por décadas o público infantil foi vitimado por esta fraude e seus pais sendo compelidos a comprarem a engenhoca e forçarem seu uso, na expectativa da correção de pseudoanormalidades criadas pela indústria e alguns colaboradores médicos. Certamente este modismo bizarro, acabou por desencadear tremenda ciumeira entre irmãos, primos, vizinhos da vítima e até colegas de aula, enfim todos desejavam igualmente a tal botinha que conferia ao usuário o status de coitadinho da mamãe e por isso mesmo merecedor de afagos paternais diferenciados. Déficits psicológicos variados, além daqueles de natureza pecuniária, podem ser facilmente identificados na grande população afetada por esta prática irracional, de franca inspiração philantrópica.

Uma outra que está em franco frenesi social é o uso de aparelhos dentários diversos. Com toda certeza, muitas pessoas exibem alterações dentárias que justificam seu emprego. Mas, será que todo este mundaréu de pessoas que vemos nas ruas ostentando aparatos ortodônticos tem real indicação para tal?

Por fim, a estúpida hidratação generosa continua liquidando pessoas idosas internadas em hospitais. Aliás, intoxicação por água, é uma causa mortis super banalizada e pouquíssimas vezes é aceita e reconhecida por nós médicos. Frascos de sorinho continuam sendo prescritos de modo anárquico, até que suas vítimas exibam sinais neurológicos óbvios de hiponatremia. Correção igualmente desastrada da mesma é o último ato desta espécie de crônica da morte anunciada. Esta sobrevém como natural conseqüência e a responsabilidade pelo desfecho funesto é rapidamente transferida para a idade da vítima. Ao invés da revolta, familiares aceitam o fenômeno de maneira dócil... afinal estava tão velhinha (o). E quanto maior for sua herança e o número de pilantras nela interessados, mais fácil ocultar fatos abomináveis. É tragicômico observar que os atestados afirmam que morreram de parada cardíaca. Esta é mais uma doença artificial, típica de hospital e somente muito raramente vista fora deste ambiente. A simples aplicação de aritmética básica (ou de bom senso) na correção de distúrbios hidroeletrolíticos em idosos seria uma medida altamente eficaz para preveni-la. Muitos morrem de sede neste planeta; porém, convenhamos, morrer intoxicado por água em um ambiente onde se supõe estar protegido, deveria ser identificado como crime hediondo. Por ironia ou conveniência social mórbida é rotulada como natural. 


\title{
PROVÉRBIO HINDU
}

Finalizando, gostaria de Ihes deixar um antigo provérbio hindu, cuja lembrança e aplicação promoveriam uma drástica redução do número de pessoas intoxicadas por medicamentos entre nós - Medicina é a arte de entreter a doença enquanto a mãe natureza faz o seu papel.

Com certeza, ele não deveria ser interpretado como um dogma religioso, mas sim como uma regra simples para um emprego sábio dos nossos venenos. E, com sinceridade, pessoas atormentadas por problemas de saúde não precisariam usar tantos medicamentos como sugere a monstruosa indústria farmacêutica. E os responsáveis por sua prescrição, jamais deveriam perder de vista o potencial tóxico que todo ele carrega consigo. E para facilitar esta compreensão, o ensino de Toxicologia - quase inexistente - deveria ser incrementado nas escolas médicas do Brasil.

Desgraçadamente a picaretagem transformou-se em um mal universal e práticas similares estão acontecendo em qualquer parte do mundo e em qualquer outra atividade também. Profissionais íntegros e de índole crítica são capazes de identificá-las com facilidade. Deles se espera reação diante da tirania mercadológica que torna insultuosa a prática médica atual.

P.S.:

Este "vômito literário" é conseqüência de trinta anos de náuseas, provocadas pela percepção de como esta profissão se tornou gradualmente refém da indústria farmacêutica. Medicina é uma arte, e aqueles que com ela se identificam, deveriam ser capazes de liderar uma insurgência contra falaciosos de todos os matizes que maculam seu exercício. A philantropia dopaminada deve ser combatida, pois do contrário, iremos acabar na vala comum do descrédito popular. E a palavra do bom curandeiro, sempre útil no alívio de qualquer sofrimento, irá perder sua eficácia. E, definitivamente, não há nenhum medicamento mais eficaz que as palavras de um médico educado, bem humorado e otimista no trato de seus pacientes. Dispenso honestidade como qualificação, pois a considero pré-requisito básico para uma prática brilhante de qualquer profissão. Que outros tipos continuem tagarelando e mentindo; todavia, nós não deveríamos cometer tal sorte de sacrilégio.

Convicto, a implantação de Disciplinas de Toxicologia em todos os Cursos de Medicina, de qualquer país, iria contribuir para os futuros médicos conhecerem os efeitos colaterais da sua profissão e minimizarem sua toxicidade. Mas, com a proliferação espantosa de tantos cursos de Medicina Brasil afora e sem qualquer controle de qualidade; não posso me iludir, isto é uma utopia. Seguiremos em direção ao pântano de maneira idêntica a outras categorias profissionais.

Finalizando, e para que não me interpretem mal, saliento - minha ética foi e sempre será devotada à profissão. E o estilo, como dizia Schopenhauer, é a fisionomia da alma. E, como tenho uma única, que se mantêm rebelde e transparente ao longo da minha existência, aproveito para expressar a ela minha gratidão.

Florianópolis, 17 de Novembro de 2008.

\author{
Dr.Paulo César Trevisol Bittencourt \\ Professor de Neurologia/UFSC \\ www.neurologia.ufsc.br \\ pcb@neurologia.ufsc.br
}




\section{DEDICATÓRIA:}

À Freya Gross, artista e pessoa inigualável, morta recentemente, vítima de grotesca iatrogenia em um hospital de Santa Catarina.

\section{DADOS DO AUTOR:}

Paulo César Trevisol Bittencourt é natural de Jacinto Machado (capital da banana), extremo sul de Santa Catarina. Graduado em Medicina pela Universidade Federal de Santa Catarina (UFSC); Neurologista pelo Hospital de Clínicas da Universidade Federal do Paraná. Especializado em Epileptologia pela Universidade de Londres e Mestre em Medicina. Atualmente é professor Adjunto de Neurologia do curso de Medicina da UFSC. É membro titular da Academia Brasileira de Neurologia desde 1986 e por vinte anos (+ -) foi presidente do Centro de Estudos do Hospital Universitário/UFSC.

RECEBIDO: 17/11/08 ACEITO:30/11/08 
